\title{
Basic English Writing: An Experimental Course Structure Against Semantic Misinterpretation In Undergraduate Student Writing
}

Fan-yu In, Feng Chia University, Taiwan

Hui-Chuan Liao, National Kaohsiung University of Applied Sciences, Taiwan

\begin{abstract}
Course designs for Basic English Writing classes vary from one course to another. The objective of this study was to investigate the semantic misinterpretation of English words found in the English compositions written by native-Chinese-speaking undergraduate students and to overcome if such a barrier occurred in the process of writing. First, this study made use of both linguistic and literary theories in an attempt of exemplifying the existence of the translation and semantic misinterpretation adopted by undergraduate students when writing in English. This hypothesis could be proved by the detached relation between the sign and the referent, or in Saussure's terminology, between the signifier and the signified, in particular in translating from Chinese into English. This study included an experimental course structure, which consisted of some feasible teaching methods. These methods were applied to Basic English Writing classes investigated in the present study. They were dictionary-consulting activities, team discussions (brainstorming as a team), sentence-making activities in which signal words were used, and team writing activities, in order to improve the student's writing skills and his or her vocabulary size. Test instruments included a pretest (pre-class questionnaires) and a posttest (a midterm writing test). Targeted students were Chinese non-English majors taking Basic English Writing (BEW) classes. The students in the treatment group performed better in the posttest than those in the control group. Moreover, the students, who failed to get into the habit of consulting English dictionaries, did not perform better than those consistently consulting English dictionaries. It seems that the experimental course structure may facilitate university students' learning of how to write in English.
\end{abstract}

Keywords: English writing, course structure, semantic misinterpretation, text analysis, t-test

\section{INTRODUCTION}

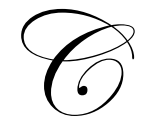

ourse designs for Basic English Writing classes vary from one course to another as well as from one teacher to another. Besides the above two variables, students who take the Basic English Writing classes can form another variable. In other words, the students with different backgrounds and in different fields may need the aid of a reformed course structure. English writing classes at some universities are offered to all students without regard to which year the student is in. Except for that consideration, students' fields may need to be taken into consideration. Therefore, with a mix of the students in different fields and in different years at university, the course structure designed for Basic English Writing (BEW) classes may need to cater for a wide range of students.

In light of variables in writing, Hinkel (1994) asserted that "Written texts represent a convergence of different stylistic, cultural, religious, ethical, and social notions, all of which comprise written discourse notions and 
frameworks" (p. 353). Hinkel's assertion comprehensively covers most variables in written texts. To nonnative-English-speaking students, especially native-Chinese-speaking undergraduate students in this study, when they write in English, they tend to first be stuck in the use of words and then in the stylistic, cultural, religious, ethical, and social differences between Chinese and English.

In general, the participants in BEW classes are beginning writers. In addition, to the non-native-English writers, English writing has been a disconcerting subject. On the one hand they recognize the importance of learning how to write in good English. On the other hand, they have a hesitation in starting to write. Their hesitations mostly originate from two reasons. First, they have learned a limited number of English words. Second, they are used to thinking in Chinese when they write in a second language. In short, the first reason has a connection to the linguistic signs, while the second reason involves the translation from Chinese to English in writing. Their translation, however, results in semantic misinterpretation of English words that are chosen in the process of translating from Chinese to English. Research has shown that there are variables in written texts. In terms of vocabulary, seven studies found that L2 writers exhibited more anxiety and difficulty with vocabulary (Arndt, 1987; Dennett, 1985; Krapels 1990; Moragne e Silva, 1991; Silva, 1993; Skibniewski, 1988; Yau, 1989). As for the translation in writing, Bernardini (2003) in her study of translation and language teaching suggested the foreign culture in translation; for example, the perception English writers have of Italian culture as exhibited by the Italian expressions in English fiction. This feature belongs to professional translation. Besides, professional translation acts as a medium between a text and an expected reader and then explicates the meaning of the former to the latter (In, 2005). In the compositions of BEW students, on the contrary, the signs of unskilled translation are perceivable. Hinkel (1994) cited Matalene (1985) that "her Chinese students' writing in English closely adhered to the classical Chinese writing tradition" (p. 354). In other words, the culture of source language (Newmark, 1988), i.e., Chinese, remains in the basic-level English writing by means of unskilled translation, which often results in semantic misinterpretation of target language, i.e., English. This is what I found in my Chinese student's English compositions, in which a shadow of Chinese writing tradition and their translation of thoughts in Chinese could be easily perceived in their midterm assignments during a semester. Matalene's study, asserting the unity between writer and reader promoted by brief images with the aid of Chinese writing tradition, might bring out a question. In terms of basic-level English texts written by Chinese undergraduate participants, the unity between the writer and reader was scarcely achieved because of unskilled writing (Raimes, 1985). Instead, Chinese writing tradition and the unskilled translation of Chinese thoughts barred the beginning writers from accustoming themselves to learning English writing skills.

This study, therefore, included some classroom activities for experiment. In addition to lectures, the experiments of conducting both individual and interactive learning activities, including dictionary-consulting activities, team discussion activities, sentence-making activities, and team writing activities in this study, may help non-English majors learn basic writing skills, such as creating the text's main idea (Arnaudet \& Barrett, 1984; Leki, 1989; Raimes, 1983, 1992; Reid, 1988), including specific and explicit details or facts to support the main idea (Arnaudet \& Barrett, 1984; Raimes, 1983, 1992; Reid, 1988) and at the end of the composition showing the writer's positions on the topic (Leki, 1989; Raimes, 1992; Reid, 1988; Zamel, 1982). In short, these basic writing skills can be summarized in three terms: topic sentence, supporting sentences, and concluding sentence (Blanchard \& Root, 2003; Fellag, 2002; Watkins, Dillingham, \& Hiers 2001).

With regard to the use of English dictionaries, a warning from Morton and Biber about a reader's common application of Oxford English Dictionary may be pragmatic for teachers to remind their students. Basically, the entries in the Oxford English Dictionary relied on the choice of the readers happened to notice; and dictionary makers found that readers generally paid more attention to unusual uses of words than common ones (Biber, 2000; Morton, 1994). This warning was included in the lectures and dictionary-consulting activities in this study. Moreover, learning lexical sets such as antonyms and synonyms may help students learn vocabulary (Channell, 1981; Neuner, 1992); however, learning related words is not a good method for initial learning (Nation 2000). This suggestion was made in the sentence-making activities and team writing activities. Skibniewski and Skibniewska (1986) found that L2 writers spent more time consulting a dictionary. Nation $(2000,2001)$ suggested that consulting a dictionary is a strategy that helps beginning writers tackle the difficulty with vocabulary and learn L2 vocabulary. 
Beginning writers will have the opportunity to overcome their problem of the use of words if they choose to resort to such reliable dictionaries as Oxford English Dictionary and Collins Cobuild English Dictionary. In order to upgrade from beginning to intermediate level, beginning writers can resort to English dictionaries when producing written texts.

In language acquisition ${ }^{1}$ (Biber, Conrad, \& Reppen, 2000), in particular a second language (L2) acquisition by university students, this study employed the idea suggested by Biber, Conrad and Reppen that was to investigate the compositions of native-Chinese-speaking writers. Instead of investigating the frequency of errors in the writing of L2 students, this study analyzed the frequency of occurrence of designated lexico-grammar features, such as the uses of intransitive verb phrases, or phrasal verbs as defined by Garderner \& Davies (2007), wh-relative clauses (Biber, Conrad, \& Reppen, 2000), and text connectives (Blanchard \& Root, 2003; Connor, 1994; In, 2006; Watkins, Dillingham, \& Hiers, 2001) in basic-level writing. The intransitive verb phrases, wh-relative clauses, and text connectives were taught and practiced in lectures, dictionary-consulting activities, team discussion activities, sentence-making activities, and team writing activities.

The study employed a pretest-and-posttest design in order to evaluate the progress of the participants' learning during the first half of this study. The participants were given a pretest, which was a pre-class questionnaire composed of background questions (Cohen, 1993) and lexico-grammar questions (see Appendix A). The pre-class questionnaire helped the participants demonstrate how they learn English. For example, had they got into the habit of consulting English dictionaries? To be precise, most students are familiar with such words as which, in, or at, but they do not know how to use them or they partly know how to use them. In that case, those words are hence seen incomplete to them because they lack the habit of looking up words in a dictionary when they choose them to write. The result of using a word without knowing how to use it is often a grammatically incorrect or badly constructed sentence. In the Saussurean structure the negative phenomenon can be explicated in this way that the signifier is entirely or partly detached from the signified. To further discuss the negative-positive phenomenon in language, Saussure (1992) had made clear that "the statement that everything in language is negative is true only if the signified and the signifier are considered separately; when we consider the sign (composed of the signified and the signifier) in its totality, we have something that is positive in its own class" (p. 723).

The above research has found and elucidated the barriers that beginning writers may confront when they write in English. This study explored these barriers from a linguistic angle and also found the relationship between writing and language acquisition. Besides, there was an attempt in this study to further describe the participants' semantic misinterpretation by means of Saussure's, Lacan's, Derrida's, and Eagleton's theories. Saussure (1992) noted that "The bond between the signifier and the signified is arbitrary" (p. 719). Arbitrariness means that the signifier has no natural connection with the signified. In the movement of signification, the signified is attached to the signifier in an arbitrary way. In Eagleton's (1996) interpretation of Saussure's view of sign, he affirmed that "there is no fixed distinction between signifiers and signifieds" (p. 111). Derrida (1992) in his "Structure, Sign and Play in the Discourse of the Human Sciences" explicated the floating ${ }^{2}$ relation between signifier and signified in light of center versus supplement ${ }^{3}$ as well as presence and absence. To continue Saussure's linguistic science, Lacan (2001) introduced an algorithm: S/s, "which is read as: the signifier over the signified, 'over' corresponding to the bar separating the two stages" (p. 1292). Instead of placing emphasis simply on the distinction or difference ${ }^{4}$

${ }^{1}$ Biber, Conrad, and Reppen (2000) divide the research in language acquisition into three major areas: "1. the first-language acquisition of very young children; 2. latter language development, such as the acquisition of literacy skills, by students at various stages; 3. second language acquisition, by children and adults (p. 172).

2 Jacques Derrida writes on the floating relation that "The movement of signification adds something, which results in the fact that there is always more, but this addition is a floating one because it comes to perform a vicarious function, to supplement a lack on the part of the signified" (p. 1123).

3 According to Jacques Derrida, "One cannot determine the center and exhaust totalization because the sign which replaces the center, which supplements it, taking the center's place in its absence - the sign is added, occurs as surplus, as a supplement" (p. 1123).

${ }^{4}$ Lacan (2001) uses the bar - to denote the distinction or difference between signifier and signified, as well as the superiority of 
between signifier and signified, Lacan (2001) pointed out the superiority or privilege of the signifier over the signified in an attempt to specify the relation between signifier and signified. All in all, the above has validated the space that separates signifier from signified before they are united in an arbitrary way in order to function in the movement of signification. The participants' semantic misinterpretation was exhibited by the detached relation between signifier (i.e., English words) and signified (i.e. Chinese connotations).

\section{Purpose Of The Study And Research Questions}

The specific purpose of this study was to examine the effects of using the experimental course structure on beginning level Chinese seniors. Two research questions were addressed by this study.

1. How well does the experimental course structure help the participants avoid diminish semantic misinterpretation when they write in English?

2. How well does the experimental course structure help the participants increase the number of occurrences of intransitive verb phrases, wh-relative clauses, and text connectives in their compositions?

\section{METHOD}

This study was conducted as a two-group controlled experiment. It involved the use of a control group and a treatment group. This section introduces three kinds of information: participants, procedures, and instruments. The subsection of participants provides a description of participants involved in the study. The subsection of procedures gives information on the experimental course structure. The subsection of instruments elaborates the evaluation and test instruments applied in the study.

\section{Participants}

In this study, there were two groups from three BEW classes. The study involved the use of a control group and a treatment group. The control group was comprised of 20 seniors. The treatment group consisted of 40 seniors. The 20 control participants were selected from the 25 students in one of the BEW classes. The 40 treatment participants were chosen from the 66 students in the other two of the BEW classes. A total of 60 participants were all non-English majors with an average beginning-level English proficiency based on two criteria: a pretest in the study and the placement test held upon entrance to the university.

The participants of both groups were selected on the basis of the last year of study at university; in other words, they were all seniors. Besides, they majored in non-English fields. Therefore, an experiment could be conducted based on the similar level of the students who were in their last year at university.

\section{Procedures}

Table 1 shows the experimental course structure designed for this study. The course structures for each group are different. The 20 control participants had taken BEW class for the first half of the semester and were given lectures and dictionary-consulting activities. The 40 treatment participants had taken the BEW class for the first half of the semester and were given lectures and such classroom activities as dictionary-consulting activities, team discussion activities, sentence-making activities, and team writing activities.

First, lectures and dictionary-consulting activities were given to both groups. Lectures were regarded as part of a basic teaching strategy in this study. Dictionary-consulting activities were conducted because of their effect on vocabulary acquisition. In this activity each student was assigned a task of looking up in a dictionary one entry from the list as Appendix B and using it to make a sentence. In this way, the student showed his comprehension of

signifier (S) over signified (s). 
the signal word assigned.

Second, team discussion activities were given to the treatment group whose participants were asked to brainstorm as a team in order to generate as many ideas as possible for a topic. In this activity each student learned from his team members. Third, sentence-making activities were conducted in the BEW classes for the treatment group. Students were asked to make a sentence in which a signal word or phrase was used. Fourth, team writing activities were accomplished during the first half of the semester as a beginner's treat. To overcome BEW learner's fear at the beginning of the semester, team writing activities were offered to help participants write as a team. After each team finished their writing, they had to share it with the whole class by writing it down on the blackboard. Accordingly, the teacher corrected and scored each team's composition. In this activity, learning and fun were achieved simultaneously.

Table 1 Course structures for two groups

\begin{tabular}{|l|l|}
\hline \multicolumn{1}{|c|}{$\begin{array}{c}\text { Control Group } \\
\mathbf{n = 2 0} \text { students }\end{array}$} & \multicolumn{1}{|c|}{$\begin{array}{c}\text { Treatment Group } \\
\mathbf{n = 4 0} \text { students }\end{array}$} \\
\hline Lecture technique & Lecture technique \\
\hline Dictionary-consulting activities & Dictionary-consulting activities \\
\hline Nil & Team discussion activities (brainstorming as a team) \\
\hline Nil & Sentence-making activities in which signal words are used \\
\hline Nil & Team writing activities \\
\hline Evaluation by a writing test & Evaluation by a writing test \\
\hline \hline
\end{tabular}

\section{Instruments}

The test instruments included a pretest and a posttest. The pre-class questionnaires are treated as a pretest. Each participant in both group completed a pre-class questionnaire (Cohen, 1993) as Appendix A. Appendix A comprised two sections. Section 1 contained questions about the basic background of the participants. Section 2 included lexico-grammar questions by which the participants showed their comprehension in the use of the parts of speech, such as pronouns, nouns, verbs, adverbs, conjunctions, and prepositions.

The posttest was a midterm writing test evaluated with three variables in accordance with text analyses (Connor, 1994). Each participant's composition was analyzed according to text analyses (Connor, 1994). The text analyses in the study consisted of three variables: intransitive verb phrases (Bibee, Johansson, Leech, Conrad, \& Finegan, 1999; Bolinger, 1971; Sawyer, 2000; Sheen, 2000), wh-relative clauses (Biber, Conrad, and Reppen, 2000), text connectives (Blanchard \& Root, 2003; Connor, 1994; In, 2006; Watkins, Dillingham, \& Hiers, 2001). Each of these variables had its own significance of evaluating the quality of English writing. The number of occurrences of the three variables was calculated by an independent two-sample t-test in SPSS. The t-test results show the answers to the two research questions about the comparison between two groups.

Both groups were tested by the same examiner, who was the teacher herself. The 60 students completed the pre-class questionnaires when they attended the first class in the semester. Each participant in both groups was tested by a midterm writing test. The effect of the experimental course structure is shown in Table 3 based on the occurrences of these three variables: intransitive verb phrase, or phrasal verbs as defined by Garderner \& Davies (2007), wh-relative clauses, and text connectives in the participants' compositions. The students read and completed the questionnaire as Appendix A. Background questions (Cohen, 1993) in Appendix A were designed to obtain a general understanding of the participants' academic and writing background. These questions were intended to discover the learning habits of the participants prior to their attendance at BEW classes. Lexico-grammar questions in Appendix A were designed to focus on an analysis of participants' proficiency in wh-relative clauses, the referent 
of pronoun, the use of intransitive verb, a real comprehension of the proper use of adverb, and the differentiation between conjunction and preposition. Such questions were created in an attempt to locate students' lexico-grammar levels before they took BEW classes.

\section{RESULTS AND DISCUSSION}

The results in the current study are divided into three subsections: results of pretest (pre-class questionnaires), t-test results of posttest (a midterm writing test), and an analysis of the semantic misinterpretation found in the results of both pretest and posttest. The results of pretest display: 1) the frequency of consulting a dictionary shown by all the participants, and 2) the participants' lexico-grammar comprehension. The t-test results of posttest reveal if there is a significant difference in each variable.

\section{Results Of Pretest (Pre-Class Questionnaires)}

Figure 1 displays the frequency of consulting a dictionary shown by all the participants in this study. Within the $60 \mathrm{BEW}$ students, 5\% of them frequently consulted an English dictionary before their attendance at BEW classes, whereas $13.33 \%$ of them frequently consulted an English dictionary after their attendance at BEW classes. Moreover, $56.66 \%$ of these 60 participants sometimes consulted an English dictionary before their attendance at BEW classes, whereas $38.33 \%$ of them sometimes consulted an English dictionary after their attendance at BEW classes. These 60 participants were divided into two groups: a control group and a treatment group. Within the control group, $10 \%$ of them frequently and $40 \%$ sometimes consulted an English dictionary before their attendance at BEW classes, whereas 5\% of them frequently and 25\% sometimes consulted an English dictionary after their attendance at BEW classes. Within the treatment group, $2.5 \%$ of them frequently and $65 \%$ sometimes consulted an English dictionary before their attendance at BEW classes, whereas $17.5 \%$ of them frequently and $45 \%$ sometimes consulted an English dictionary after their attendance at BEW classes. A habit of looking up words in an English dictionary theoretically helps the writer maintain and improve his proficiency in English (Nation, 2000). Instead of frequently consulting the dictionary, more participants chose to sometimes consult the dictionary; yet, it appears that a drop in consulting the dictionary take a brief pause after these participants' attendance at BEW classes. On the contrary, in my other studies the decrease in the frequency of consulting the dictionary remained steady after the participants entered the university chosen for study.

Figure 1

Frequency of consulting a English dictionary: frequently (F), sometimes (S), rarely (R), and never (N) in both groups

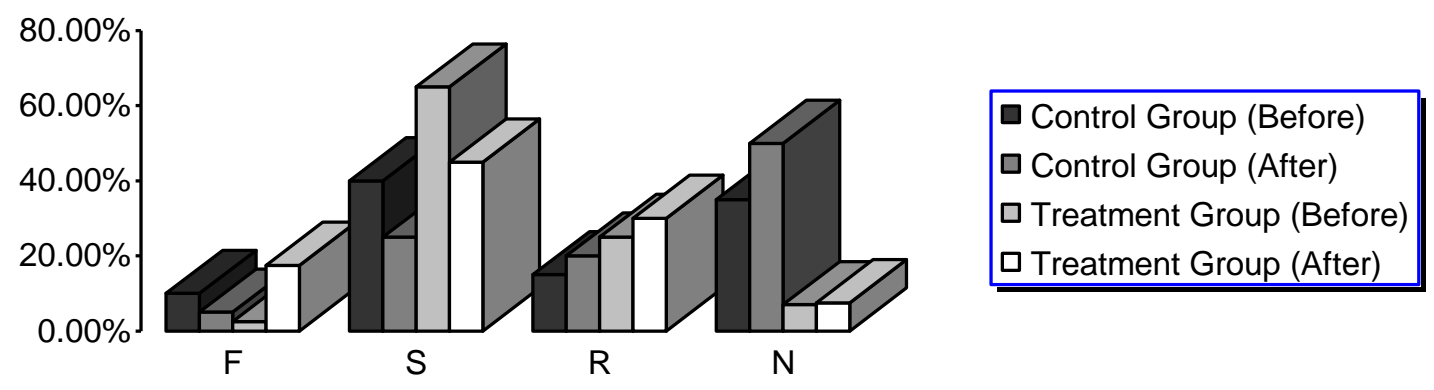

\section{Question 1}

Table 2 demonstrates the lexical-grammar comprehension found in pre-class questionnaires. In response to the imperative instruction Use this relative pronoun, "which," to make a sentence, $43.33 \%$ of the participants were 
able to make a sentence with a wh-relative clause. Of this 43.33\%, 6 participants in the control group and 20 participants in the treatment group proved their ability to use a wh-relative clause to make a sentence. And of this $43.33 \%, 3.33 \%$ frequently and $18.33 \%$ sometimes consulted an English dictionary before their attendance at BEW classes. By contrast, $8.33 \%$ frequently and $13.33 \%$ sometimes consulted an English dictionary after their attendance at BEW classes.

Participants who received a $\mathrm{C}$ in Question 1 showed their capability to make a connection between the relative pronoun, which, and the antecedent noun that it replaces. In other words, such students demonstrated the ability to identify the connection between the signifier (which) and the signified (referent noun); and this exhibited the positive phenomenon (Saussure, 1992) in these students' L2 acquisition. Noticeably, no decline is seen in the frequency of consulting the dictionary after the participants' attendance at BEW classes. The teacher's emphasis on consulting a dictionary may have a certain influence on stopping the drop in this regard.

\section{Question 2}

Though 56.67\% of the participants failed to receive a C in Question 1, they had an opportunity to prove their ability to locate the noun to which the relative pronoun, who, refers in Question 2. In reply to Question 2, $76.66 \%$ of the participants received a C. And of this $76.66 \%$, there were 8 participants in the control group and 38 participants in the treatment group. Within this $76.66 \%, 5 \%$ frequently and $31.66 \%$ sometimes consulted an English dictionary before their attendance at BEW classes. On the contrary, $16.66 \%$ frequently and $25 \%$ sometimes consulted an English dictionary after their attendance at BEW classes. In terms of the results of Question 2, it seems that $\mathrm{C}$ receivers rely not only on the dictionary but also on other learning methods, for example, sentence-making activities in the experimental course structure.

\section{Question 3}

Question 3 was designed to evaluate participants' attention to intransitive verb phrases. $35 \%$ of BEW students succeeded in Question 3, within which there were 10 participants in the control group and 11 participants in the treatment group. Of this 35\%, 3.33\% frequently and 18.33\% sometimes consulted an English dictionary before their attendance at BEW classes. In contrast, $10 \%$ frequently and 15\% sometimes consulted an English dictionary after their attendance at BEW classes. Such participants exhibited their attention to the prepositions attached to the intransitive verb phrases by looking up the intransitive verbs in an English dictionary. A slight increase is seen in the frequency of consulting the dictionary after the participants' attendance at BEW classes.

\section{Question 4}

Question 4 was designed to recognize the participants' comprehension of adverbs. The design may be involved with Strevens' (1987) finding that cultural differences and notions pertaining to writing may become the barrier between the learner and the target language. Question 4 is related to the interpretation because, for example, the Chinese translation of the adverb, "recently," hardly indicates how to use this word properly. In English, the adverb, "recently," is commonly used in the present perfect or past tense sentence. However, Chinese beginning students' interpretation of English adverbs is often far away from the proper use of them in accordance with English grammar, mainly because they fail to notice the English translations of English words in a Chinese/English bilingual dictionary. A thorough learning of English adverbs and adjectives is beneficial to the application of rhetorical constructs to English compositions. Hinkel (1994) indicated that "Bloom's (1981) Chinese participants disliked the rhetorical constructs that they encountered in English texts" (p. 373). The importance of teaching rhetorical constructs in basic-level writing has been emphasized in the studies on writing (Flower, 1984; Memering \& O'Hare, 1983).

$28.33 \%$ of the participants succeeded in using the adverb, "recently," to make a sentence, within which there were 6 participants in the control group and 11 participants in the treatment group. In view of the results of 
Question 4, of this $28.33 \%$, 5\% frequently and 25\% sometimes consulted an English dictionary before their attendance at BEW classes. As compared to the frequency before entrance, $13.33 \%$ frequently and $16.66 \%$ sometimes consulted an English dictionary after their attendance at BEW classes. The low percentage of C receivers indicates that a larger number of the participants may have a semantic misunderstanding of the adverb "recently" and a less concentration on the meaning of other adverbs. A balance, neither up nor down, is seen in both registers: frequently and sometimes. It seems that $\mathrm{C}$ receivers rely less on the dictionary and more on other learning methods in the experimental course structure.

\section{Questions $5 \& 6$}

Questions 5 and 6 were designed to have an understanding of the participants' attention to the use of prepositions (Connor, 1990) and conjunctions. In regard to Question 5, 61.66\% of the participants received a C, within which there were 12 participants in the control group and 25 participants in the treatment group. Of this $61.66 \%, 3.33 \%$ frequently and $28.33 \%$ sometimes consulted an English dictionary before their attendance at BEW classes. Conversely, $13.33 \%$ frequently and $16.66 \%$ sometimes consulted an English dictionary after their attendance at BEW classes. The increase in C receivers' frequency of frequently consulting the dictionary after their attendance at BEW Classes may indicate the importance of the teacher's emphasis on dictionary-consulting practice. As to Question 6,76.66\% of the participants received a C, within which there were 9 participants in the control group and 37 participants in the treatment group. And of this $76.66 \%, 1.66 \%$ frequently and $31.66 \%$ sometimes consulted an English dictionary before their attendance at BEW classes. In contrast, $13.33 \%$ frequently and $28.33 \%$ sometimes consulted an English dictionary after their attendance at BEW classes. Similar to Questions 2 and 5, the results imply that $\mathrm{C}$ receivers rely not only on the dictionary but also on other learning methods, for example, lectures in the experimental course structure.

Table 2

Lexico-grammar comprehension found in pre-class questionnaires: correctness (C) versus incorrectness (I) in both groups $(\mathbf{N}=60)$

\begin{tabular}{|c|c|c|c|c|}
\hline \multicolumn{3}{|c|}{$\begin{array}{l}\text { Control Group } \\
\quad(\mathbf{n}=\mathbf{2 0})\end{array}$} & \multicolumn{2}{|c|}{$\begin{array}{l}\text { Treatment Group } \\
\qquad(\mathbf{n}=\mathbf{4 0})\end{array}$} \\
\hline \multirow[t]{3}{*}{1.} & \multicolumn{4}{|c|}{ Use this relative pronoun, "which," to make a sentence. } \\
\hline & $\mathrm{C}$ & $\mathrm{I}$ & $\mathrm{C}$ & I \\
\hline & 6 & 14 & 20 & 20 \\
\hline \multirow[t]{3}{*}{2.} & \multicolumn{4}{|c|}{$\begin{array}{l}\text { Workers who received the wages can survive without worrying about money. Which word(s) below is what the relative } \\
\text { pronoun, "who," in the above sentence signifies? }\end{array}$} \\
\hline & $\mathrm{C}$ & $\mathrm{I}$ & $\mathrm{C}$ & I \\
\hline & 8 & 12 & 38 & 2 \\
\hline \multirow[t]{3}{*}{3.} & \multicolumn{4}{|c|}{ Which sentence below is obviously wrong? } \\
\hline & $\mathrm{C}$ & $\mathrm{I}$ & $\mathrm{C}$ & I \\
\hline & 10 & 10 & 11 & 19 \\
\hline \multirow[t]{3}{*}{4.} & \multicolumn{4}{|c|}{ Use this adverb, "recently," to make a sentence. } \\
\hline & $\mathrm{C}$ & I & $\mathrm{C}$ & I \\
\hline & 6 & 14 & 11 & 29 \\
\hline \multirow[t]{3}{*}{5.} & \multicolumn{4}{|c|}{ Choose a word from below to complete this conjunctional phrase: for } \\
\hline & $\mathrm{C}$ & I & $\mathrm{C}$ & I \\
\hline & 12 & 8 & 25 & 25 \\
\hline \multirow[t]{3}{*}{6.} & Choose a v & this & & \\
\hline & $\mathrm{C}$ & I & $\mathrm{C}$ & I \\
\hline & 9 & 11 & 37 & 3 \\
\hline
\end{tabular}




\section{T-Test Results Of Posttest (Midterm Writing Test)}

The independent two-sample t-test in SPSS concerning the number of three variables generated by two groups yielded significant results, as demonstrated by Table 3. Table 3 displays the independent t-test results of three variables: intransitive verb phrase, wh-relative clauses, and text connectives. A significant difference is shown in two variables: wh-relative clauses and text connectives.

Based on Levene's test for equality of variances, the result of intransitive verb phrase, $\mathrm{F}=0.048$, $p=0.859>0.05$, indicated no significant difference between the control group and treatment group. Second, the result of wh-relative clause, $\mathrm{F}=15.037, p=0.023<0.05$, indicated a significant difference between the control group and treatment group. Treatment group outperformed control group in this regard. In terms of text connective, the F value of $1.811(p=0<0.05)$ indicated a significant difference between the control group and treatment group. Therefore, treatment group outperformed control group.

Table 3 Independent t-test results: mean scores of two groups $(\mathbf{N}=60)$

\begin{tabular}{l|c|c|c|c|c|c|c}
\hline \hline & & \multicolumn{2}{|c|}{ Intransitive verb phrase } & \multicolumn{2}{|c|}{ Wh-relative clause } & \multicolumn{2}{|c}{ Text connective } \\
\hline Group & $\mathrm{n}$ & Mean & SD & Mean & SD & Mean & SD \\
\hline Control & 20 & 0.50 & 0.51 & 0 & 0 & $1.5^{*}$ & 0.82 \\
\hline Treatment & 40 & 0.52 & 0.50 & $0.12^{*}$ & 0.33 & $3.47^{*}$ & 1.08 \\
\hline \hline
\end{tabular}

$* p<0.05$ (two-tailed)

$\underline{\text { Intransitive Verb Phrases }}$

Intransitive verb phrases occurred more in the texts of control group. 10 occurrences were found in the 20 texts of control group as compared to 19 occurrences in the 40 texts of treatment group. An intransitive verb phrase consists of a verb and a preposition. In terms of multiword structures, four studies found the importance of multiword learning in developing a learner's innate fluency (Gardner \& Davies, 2007, Moon, 1997; Schmitt, 2004; Wray, 2000, 2002). Moreover, Gardner and Davies (2007) asserted that phrasal verbs are important to English because they enrich the language. Besides, Ferris (1994) noted that "Connor (1990) found that the use of a factor composed of passives, nominalizations, conjunctions, and prepositions was positively correlated with compositions' holistic scores" (p. 147). Thus the use of prepositions in the participants' compositions may indicate a higher level of English proficiency. The more occurrences of prepositions in the participants' compositions are used properly, the higher level of English proficiency the participants exhibit. In comparison to the features exhibited by the higher proficiency writers, Ferris (1994) specified that "the lower proficiency writers tended to rely on repetition to promote textual cohesion (Halliday \& Hasan, 1976)" (p. 417). Such repetitions as "be made of" or "let somebody feel" were shown repeatedly in the participants' compositions in the midterm writing test, indicating a limited number of learned vocabularies.

\section{Wh-relative Clauses}

Wh-relative clauses may be the most interesting in the results of the midterm writing test because it demonstrates the semantic misinterpretation in the participants' compositions. The results of wh-relative clauses are lined with the results of Question 1 in Pretest. A small amount of occurrences of wh-relative clauses were found in the compositions of the treatment group, which was though higher than none of wh-relative clauses found in the compositions of the control group; hardly was it a good improvement as a whole. Nevertheless, this tiny improvement might be achieved by the teaching methods other than the dictionary-consulting activities because no occurrence of wh-relative clauses was found in the compositions of the control group, which was not given team discussion activities, sentence-making activities, and team writing activities. A wh-relative clause must start with the 
relative pronoun - which or who - that replaces the noun precedes it. As exemplified by Saussurean signifier and signified in the model of relative pronoun and its antecedent noun, the relative pronoun is equivalent to the signifier, whereas the antecedent noun is the signified. When a beginning writer is unable to locate the antecedent noun to which the relative pronoun-which or who-refers in a complete sentence with a wh-relative clause, the link between Saussurean signifier and signified is obviously missing. This missing link demonstrates the negative phenomenon in Saussurean structure. In Eagleton's (1996) interpretation of Saussure's view of sign, he affirmed that "there is no fixed distinction between signifiers and signifieds" (p. 111).

In the case of a beginning writer unable to locate the antecedent noun which the relative pronoun - which or who-signifies, the negative phenomenon appears because of the missing linkage between signifier and signified demonstrated by the beginning writer's semantic misinterpretation of what the relative pronoun-which or who-signifies. Besides, such a missing linkage between signifier and signified exists in "an anaphoric relation between a pronoun and its antecedent" in Reinhart's theory ${ }^{5}$ (Hintikka \& Sandu, 1991, p. 143). Quiet commonly, when a beginning writer who is unable to identify the antecedent noun that the relative pronoun - which or who-signifies, he is also incapable of locating the antecedent noun that a pronoun denotes. To summarize, the negative phenomenon in the model of relative pronoun and its antecedent noun coexists with that in the model of pronoun and its antecedent, especially in basic-level compositions.

\section{$\underline{\text { Text Connectives }}$}

Text connectives (Blanchard \& Root, 2003; Connor, 1994; In, 2006; Watkins, Dillingham, \& Hiers, 2001) occur 30 times in the 20 compositions of the control group in comparison to the 139 occurrences in the 40 compositions of the treatment group. In this area the gap between the control group and treatment group seems to widen presumably by classroom activities, such as lectures, sentence-making activities and team writing activities. To consider the ratio of 30 to 139 , the treatment group used text connectives more frequently in their writing. Connor (1994) indicated the recent tendency of text analyses in which "metadiscoursal analyses have been applied to analyses of students' writing" (p. 683). As per Connor (1994), "Metadiscoursal taxonomies include text connectives (e.g., first, next, however), illocution markers (e.g., to sum up, to give an example), hedges (e.g., might, perhaps), and emphatics (e.g., clearly, obviously)—which skillful writers use effectively" (p. 683). In my BEW classes, I have grouped text connectives, illocution markers, and emphatics by their shared function in sentence and call them signal words in order to provide beginning students with an easy way of learning and identifying such words. Such signal words (Blanchard \& Root, 2003; Fellag, 2002; In, 2006) aim to connect from one idea to the next so as to make a coherence throughout a paragraph and/or a composition.

\section{Semantic Misinterpretation}

The results of pretest lend support to the assumption that the beginning writers' semantic misinterpretation of certain English words is shown by their compositions. To explicate their semantic misinterpretation, two phenomena - negative and positive - are appropriate in this regard. In the negative phenomenon (Saussure, 1992), the missing linkage between Saussurean signifier and signified is shown by a beginning writer's incapability of connecting the relative pronoun to its antecedent noun and/or linking a pronoun to its antecedent. On the contrary, in the positive phenomenon (Saussure, 1992) the signifier and signified are connected by a higher proficiency writer because in such a case, he connects the signifier with the signified in an arbitrary way that is supported by his higher proficiency in lexis. Furthermore, it is likely that a higher-level writer has the capability to pair a signifier with a signified insofar as in the model of pronoun and its antecedent.

The experimental course structure was intended to diminish the semantic misinterpretation of English

\footnotetext{
5 Hintikka and Sandu (1991) elucidate Reinhart's theory that "an anaphoric relation between a pronoun and its antecedent is possible only when the former is c-commanded by the latter" (p. 143). For example, in the sentence The woman who was here yesterday said she lost her purse, she is the anaphoric substitute of 'the woman.'
} 
words in beginning writers' compositions. With the aid of such teaching methods as team discussion activities, sentence-making activities, and team writing activities, the treatment group performed slightly better than the control group in the area of wh-relative clauses, and significantly better than the control group in the area of text connectives. Though the outcome is not overwhelmingly satisfied, it is at least a good start to design a BEW class based on the experimental course structure suggested by this report.

\section{CONCLUSION}

This study attempted to assess the experimental course structure suggested by the author. The results of pretest indicate the possibility of beginning writers' semantic misinterpretation of certain English words. In response to the first research question, the t-test results of posttest display a positive influence on diminishing the participants' semantic misinterpretation of certain parts of speech in English, for example, wh-relative pronouns. Next, in reply to the second research question, the t-test results of posttest provide evidence that there is a significant difference between the control group and treatment group in two variables: wh-relative clause and text connective. They also imply that the experimental course structure may help the beginning writers produce relatively coherent compositions when compared with their previous writings.

The overall results subvert the ordinary or traditional role of translation as ascribed to a professional level. Chinese students' English writing involves translation from Chinese into English. A beginning writer in effect makes use of translation when he writes in English even without any training in translation. Therefore, a visible disintegration between what he thinks in Chinese (the referent) and what he writes in English (the sign) becomes a challenge for the student himself and the teacher to overcome. And this is what was called semantic misinterpretation in this study. A recommendation in solving this problem or enhancing the student's capability to elucidate what he thinks in his composition is that the teacher emphasizes in class the importance of looking up both familiar and unfamiliar English words in such reliable dictionaries as Oxford English Dictionary and Collins Cobuild English Dictionary. Although in my other studies the decrease in the frequency of consulting the dictionary remained steady after the participants entered the university, it is likely that the decrease takes a pause in this study due to the repeated emphasis of the importance of consulting the dictionary by the teacher. This may be regarded as a good start to continue this practice.

In addition to a regular acquisition of English words, the experimental course structure suggested here in this study may be part of the feasible solutions to the barriers that beginning writers confront. These classroom activities, including lectures, dictionary-consulting activities, team discussion activities, sentence-making activities, and team writing activities though make a positive effect on the improvement of BEW students' English writing, they are regarded as potential teaching methods for a long-term study. In other words, they can be conducted throughout this semester and then the comparison of the results of this study and the next study may be of interest. Furthermore, they can be replicated in English Writing classes for other participants and then the results of cumulative studies may provide a useful contribution.

\section{AUTHOR INFORMATION}

Fan-yu In is a lecturer at Feng Chia University in Taichung, Taiwan, R.O.C. She specializes in English teaching, vocabulary acquisition, and English literature. Her current research interests include text analyses and translation in English writing, and move to experimenting with more analytic approaches in text analyses.

Hui-Chuan Liao is an assistant professor at National Kaohsiung University of Applied Sciences in Taiwan, R.O.C. She specializes in English teaching and ESP study. Her research interests include peer learning, reading and writing instruction, and teaching ESP in the EFL context. 


\section{REFERENCES}

1. Arnaudet, M., \& Barrett, M. E. (1984). Approaches to academic reading and writing. Englewood Cliffs, NJ: Prentice Hall.

2. Arndt, V. (1987). Six writers in search of texts: A protocol-based study of L1 and L2 writing. ELT Journal, 41(4), 257-266.

3. Bernardini, S. (2003). Designing a corpus for translation and language teaching: The CEXI experience. TESOL Quarterly, 37(3), 528-537.

4. Biber, D., Conrad, S., \& Reppen, R. (2000). Corpus linguistics: Investigating language structure and use. Cambridge: Cambridge University Press.

5. $\quad$ Blanchard, K., \& Root, C. (2003). Ready to write: A first composition text. New York: Longman.

6. Bloom, A. (1981). The linguistic shaping of thought. Hillsdale, NJ: Erlbaum.

7. Channell, J. (1981). Applying semantic theory to vocabulary teaching. ELT Journal, 35, 115-122.

8. Cohen, D. (1993). The Production of Speech Acts by EFL Learners. TESOL Quarterly, 27, 33-56.

9. Connor, U. (1990). Linguistic/rhetorical measures for international student persuasive writing. Research in the Teaching of English, 24, 67-87.

10. Connor, U. (1994). Text analysis. TESOL Quarterly, 28(4), 682-684.

11. Dennett, J. (1985). Writing technical English: A comparison of the process of native English and native Japanese speakers. Dissertation Abstracts International, 46(11), 3257A.

12. Derrida, J. (1992). Structure, sign and play in the discourse of the human sciences. In H. Adams (Ed.), Critical theory since Plato (pp. 1117-1126). Orlando, FL: University of Washington.

13. Eagleton, T. (1996). Literary theory: An introduction. Oxford: Blackwell.

14. Fellag, R. (2002). Write ahead: skills for academic success. New York: Longman.

15. Ferris, D. (1994). Lexical and Syntactic Features of ESL Writing by Students at Different Levels of L2 Proficiency. TESOL Quarterly, 28(2), 414-420.

16. Flower, L. (1984). Writer-based prose: A cognitive basis for problems in writing. In S. Mckay (Ed.), Composing in a second language (pp. 16-42). Rowley, MA: Newbury House.

17. Gardner, D., \& Davies, M. (2007). Pointing out frequent phrasal verbs: A corpus-based analysis. TESOL Quarterly, 4l(2), 339-359.

18. Halliday, M. A. K., \& Hasan, R. (1976). Cohesion in English. London: Longman.

19. Hinkel, E. (1994). Native and nonnative speakers' pragmatic interpretations of English texts. TESOL Quarterly, 28(2), 353-376.

20. Hintikka, J., \& Sandu, G. (1991). On the methodology of linguistics: A case study. Oxford: Basil Blackwell.

21. In, Fan-yu. (2005). Various translation skills. Taipei, Taiwan: Princeton.

22. In, Fan-yu. (2006). Various writing skills. Taipei, Taiwan: Princeton.

23. Krapels, A. (1990). The interaction of first and second language composing: Process and rhetorics. Dissertation Abstracts International, 51(12), 4045A.

24. Lacan, J. (2001). The agency of the letter in the unconscious. In V. B. Leitch (Ed.), The Norton anthology of theory and criticism (pp. 1290-1302). New York: Norton.

25. Leki, I. (1989). Academic writing: Techniques and tasks. New York: St. Martin's Press.

26. Matalene, C. (1985). Contrastive rhetoric: An American writing teacher in China. College English, 47, 789-807.

27. Memering, D., \& O'Hare, F. (1983). The writer's work. Englewood Cliffs, NJ: Prentice Hall.

28. Moon, R. (1987). Vocabulary connections: Multi-word items in English. In N. Schmitt \& M. McCarthy (Eds.), Vocabulary: Description, acquisition and pedagogy (pp. 40-63). Cambridge: Cambridge University Press.

29. Moragne e Silva, M. (1991). Cognitive, affective, social, and cultural aspects of composing in a first and second language: A case study of one adult writer. Dissertation Abstracts International, 52(12), 4249A.

30. Morton, C. (1994). The Story of Webster's Third: Philip Gove's Controversial Dictionary and its critics. Cambridge: Cambridge University Press. 
31. Nation, P. (1989) Dictionaries and language learning. In Learners' Dictionaries: State of the Art M.L.Tickoo (ed.), RELC Anthology Series 23: 65-71.

32. Nation, P. (2000). Learning vocabulary in lexical sets: Dangers and guidelines. TESOL Journal, 9(2), 6-10.

33. Nation, P. (2001). Learning vocabulary in another language. Cambridge: Cambridge University Press.

34. Neuner, G. (1992). The role of experience in a content- and comprehension-oriented approach to learning a foreign language. In P. J. L. Arnaud \& H. Béjoint (Eds.), Vocabulary and applied linguistics (pp. 156-166). London: Macmillan.

35. Newmark, P. (1988). A textbook of translation. New York: Prentice Hall.

36. Raimes, A. (1983). Techniques in teaching writing. Oxford: Oxford University Press.

37. Raimes, A. (1985). What unskilled ESL students do as they write: A classroom study of composing. TESOL Quarterly, 19, 229-258.

38. Raimes, A. (1992). Exploring through writing (2 $2^{\text {nd }}$ ed.). New York: St. Martin's Press.

39. Reid, J. (1988). The process of composition. Englewood Cliffs, NJ: Prentice Hall.

40. Reinhart, T. (1983). Anaphora and Semantic Interpretation. London: Croom Helm.

41. Saussure, F. de. (1992). Course in general linguistics. In H. Adams (Ed.), Critical theory since Plato (pp. 718-726). Orlando, FL: University of Washington.

42. Schmitt, N. (2004). Formulaic sequences: Acquisition, processing and use. Amsterdam: John Benjamins.

43. Silva, T. (1993). Toward an understanding of the distinct nature of L2 writing: The ESL research and its implications. TESOL Quarterly, 27(4), 657-675.

44. Skibniewski, L. (1988). The writing processes of advanced foreign language learners in their native and foreign languages: Evidence from thinking aloud protocols. Studia Anglica Posnaniensia, 21(3), 177-186.

45. Skibniewski, L., \& Skibniewska, M. (1986). Experimental study: The writing process of intermediate/advanced foreign language learners in their foreign and native languages. Studia Anglica Posnaniensia, 19(3), 142-163.

46. Strevens, P. (1987). Cultural barriers to language learning. In L. Smith (Ed.), Discourse across cultures (pp. 169-178). Englewood Cliffs, NJ: Prentice Hall.

47. Watkins, F. C., Dillingham, W. B., \& Hiers, J. (2001). Practical English handbook. New York: Houghton Mifflin.

48. Wray, A. (2000). Formulaic sequences in second language teaching: Principle and Practice. Applied Linguistics, 21, 463-489.

49. Wray, A. (2002). Formulaic language and the lexicon. Cambridge: Cambridge University Press.

50. Yau, M. (1989, March). A quantitative comparison of L1 and L2 writing processes. Paper presented at the $23^{\text {rd }}$ Annual TESOL Convention, San Antonio, Texas.

51. Zamel, V. (1982). Writing one's way into reading. TESOL Quarterly, 26, 463-486. 


\section{APPENDIX A:}

\section{Pre-Class Questionnaire}

\section{Background}

1. Field of study

2. You are a _ freshman (FR), _ sophomore (SO), _ junior (JU), or _ senior (SE).

3. Writing in English in the past and currently:

In the past: frequently

Currently: frequently sometimes sometimes rarely rarely

4. Consulting an English dictionary before and after the attendance at BEW classes:

Before: frequently sometimes rarely never

After: frequently sometimes rarely never

Lexico-grammar

1. Use this relative pronoun, "which," to make a sentence.

2. Workers who received the wages can survive without worrying about money. Which word(s) below is what the relative pronoun, "who," in the above sentence signifies?
a. wages
b. money
c. workers
d. survivors

3. Which sentence below is obviously wrong?

a. The teacher is willing to teach a class composed of 20 students.

b. The teacher is willing to apply a new position.

c. The teacher is willing to talk with his students.

d. The teacher is willing to remind his students of the exam.

4. Use this adverb, "recently," to make a sentence.

5. Choose a word from below to complete this conjunctional phrase: for
e. relevant
f. including
g. first time
h. anything

6. Choose a word from below to complete this phrase:
i. between
j. on
k. at
1. in 
APPENDIX B:

Common Signal Words

(Extracts from Various Writing Skills by Fan-yu In)

\begin{tabular}{|c|c|c|c|}
\hline $\begin{array}{l}\text { a moment ago } \\
\text { a short time ago }\end{array}$ & $\begin{array}{l}\text { at the moment of } \\
\text { at this rate }\end{array}$ & $\begin{array}{l}\text { in addition to } \\
\text { in all event }\end{array}$ & $\begin{array}{l}\text { in the upper right } \\
\text { in theory }\end{array}$ \\
\hline about & because & in all respects & in this regard \\
\hline above & before & in any case & in view of \\
\hline above all & before long & in any event & instead of \\
\hline according to & behind & in back of & last but not least \\
\hline accordingly & below & in between & last of all \\
\hline across & beneath & in brief & lately \\
\hline after & beside & in comparison with & later \\
\hline after all & besides & in conclusion & later on \\
\hline afterward & between & in consequence & meanwhile \\
\hline against & but & in contrast & moreover \\
\hline all in all & by all means & in contrast to & most importantly \\
\hline all of a sudden & by and by & in effect & most of all \\
\hline also & by and large & in either event & mostly \\
\hline and then & by the way & in every sense & near \\
\hline another reason & concerning & in every way & nevertheless \\
\hline anyhow & consequently & in fact & next \\
\hline anyway & conversely & in front of & next to \\
\hline as & during & in general & nonetheless \\
\hline as a consequence & especially & in opposition to & on \\
\hline as a consequence of & even so & in particular & on account of \\
\hline as a matter of course & eventually & in practice & on average \\
\hline as a matter of fact & ever since & in regard to & on balance \\
\hline as a result & finally & in relation to & on both sides \\
\hline as a result of & first & in reply to & on the contrary \\
\hline as a rule & first of all & in respect of & on the end \\
\hline as compared with & for & in response to & on the grounds of \\
\hline as for & for a start & in short & on the left \\
\hline as of & for all & in spite of & on the left side \\
\hline as opposed to & for example & in sum & on the left side of \\
\hline as per & for instance & in summary & on the one hand \\
\hline as soon as & for the most part & in terms of & on the other hand \\
\hline as to & for the rest & in the back & on the right \\
\hline at & from the beginning & in the beginning & on the right side \\
\hline at any rate & from the start & in the case of & on the right side of \\
\hline at first & furthermore & in the center & on the whole \\
\hline at last & generally & in the end & on top of \\
\hline at least & hence & in the front & one reason \\
\hline at length & however & in the left center & one way or another \\
\hline at most & in & in the lower left & over \\
\hline at one time & in a general sense & in the lower right & over and above \\
\hline at that rate & in a manner & in the matter of & overall \\
\hline at the beginning of & in a sense & in the meantime & recently \\
\hline at the center of & in a way & in the middle of & regarding \\
\hline at the end of & in a word & in the right center & second \\
\hline at the moment & in addition & in the upper left & since \\
\hline
\end{tabular}


so

specifically

still

subsequently

such as

thanks to

the most important

then

third

thus

to start with

to sum up

to the left

to the left of

to the right

to the right of

under

versus

whereas

while

with all

with reference to

with regard to

with respect to

yet 